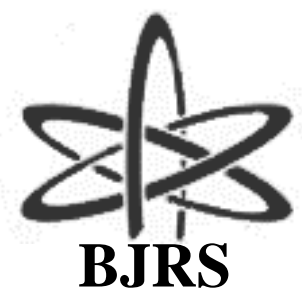

\author{
BRAZILIAN JOURNAL \\ $\mathrm{OF}$ \\ RADIATION SCIENCES \\ 08-03A (2020) 01-15
}

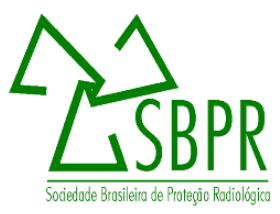

\title{
Numerical and experimental investigation of the water flow through PWR spacer grids
}

\author{
CASTRO $^{1}$ H.F.P., Vidal ${ }^{2}$ G.A.M., Vieira ${ }^{2}$ T.A.S., Silva² V.V.A., Campolina ${ }^{2}$ D.A.M., Barros ${ }^{2}$ G.P., \\ Gonçalves $^{2}$ R.C., Santos ${ }^{1,2}$ A.A.C., Veloso ${ }^{1}$ M.A.F. \\ ${ }^{1}$ Departamento de Engenharia Nuclear, Universidade Federal de Minas Gerais - UFMG Av. Presidente Antnio Carlos, 6.627 \\ 31270-901 Belo Horizonte - MG, Brazil \\ higor.fabiano@gmail.com; aacs@cdtn.br;dorafortini@ufmg.br \\ ${ }^{2}$ Centro de Desenvolvimento da Tecnologia Nuclear (CDTN/CNEN) Av. Presidente Ant'onio Carlos, 6.627 \\ 31270-901 Belo Horizonte - MG, Brazil
}

guiaugustovidal@hotmail.com; tiago.vieira.eng@gmail.com; vitors@cdtn.br; campolina@cdtn.br; graiciany.barros@cdtn.br;

cabralrebecag@gmail.com;aacs@cdtn.br

\begin{abstract}
Spacer grids are one of main components of a Pressurized Water Reactor (PWR) fuel assembly. These devices are used to improve heat transfer between rod bundles and the water flow, by increasing turbulence and mixture of this flow, they are also responsible to maintain the rod bundles equally spaced, playing a major structural role on the system. On the other hand the spacer grids increases the pressure drop of the system. Experimental and Computational Fluid Dynamics (CFD) analysis have been used to understand how spacer grids affect the water flow. These analysis are important to enhance spacer grids thermal-hydraulic performance. This paper aims to investigate numerically and experimentally the water flow through PWR spacer grids. The numerical and experimental investigations have been carried out for a $5 \times 5$ rod bundle with spacer grids at the Nuclear Technology Development Center (CDTN) in Belo Horizonte, Brazil. At CDTN, measurements of the velocity components are acquired with a 2D LDV (Laser Doppler Velocimetry) system and the numerical results are obtained using ANSYS CFX code. The measurements are obtained at one height
\end{abstract}


downstream from a spacer grid and compared to CFD simulations at Reynolds number of 5.4x10 ${ }^{4}$. Results show good agreement between both methodologies. The great repeatability and low experimental uncertainty evaluated $(<1.24 \%)$ in this work are suitable results for CFD models validations.

Keywords: Spacer grids, LDV, CFD, Thermo-hydraulic, PWR

\section{INTRODUCTION}

The fuel assemblies are the main devices present in a PWR core. They are formed by fuel rod bundles with control rods between them, bottom and top nozzles, and spacer grids. The spacer grids keep these rod bundles organized in square arrays with $16 \times 16$ or $17 \times 17$ rods typically. Spacer grids also improve heat transfer from rod surface to water by increasing the turbulence. However the local pressure drop also increase on account of spacer grids which enhance the energy requirement by primary circuit pumps [1].

In the past years, researches have been carried out to study these phenomena of turbulence and pressure drop caused by spacer grids in order to achieve an optimized system [2, 3, 4]. The turbulence has been measured mainly by Laser Doppler Velocimetry (LDV) and Particle Image Velocimetry (PIV) [5, 6]. With these techniques is possible to see some specifics patterns in the flow e.g. cross-flow (mixture flow between subchannels) and swirl-flow (mixture flow inside subchannel).

The flow through spacer grids has also been studied numerically using the Computational Fluid Dynamics (CFD) method that enables the assessment of details of the flow [3, 4, 6, 15, 16, 17].

The aim of this article is to present the ongoing efforts to investigate numerically and experimentally the velocity profiles and flow behavior of water flow through PWR spacer grids.

\section{EXPERIMENTAL METHODOLOGY}

The experiments were performed at the Thermal-Hydraulic and Neutronics Laboratory - LTHN of CDTN (Nuclear Technology Development Center) were a loop was designed and constructed for 
the study of flow through representative sections of fuel bundles. A description of the experimental facility, instrumentation and measurement methodology is presented in the following sections.

\subsection{The Air-Water Circuit and Tests Section}

The general diagram of the Air-Water Circuit (AWC) where experiments were performed can be seen in Figure 1. In this hydraulic circuit a centrifugal pump with 15HP was used to propel water from a water tank with capacity of 1000 liters to tests section. The tests section was built with two stainless steel sides, the other sides and the top part are acrylic windows to allow optical access by the 2D-LDV system which was used to measure velocities profiles. The water flow rate was evaluated by an orifice plate made according to ISO 5167 [8] and differential pressure transmitter measurements, $\mathrm{DP}_{\mathrm{o}}$. The temperature was measured by two type $\mathrm{J}$ thermocouples and system pressure, $\mathrm{P}_{\mathrm{st}}$, by a pressure transducer. Table 1 shows ranges and uncertainties from the used differential pressure transmitters. Calibration of these devices were carried in house according to LTHN procedures [9] [10]. 


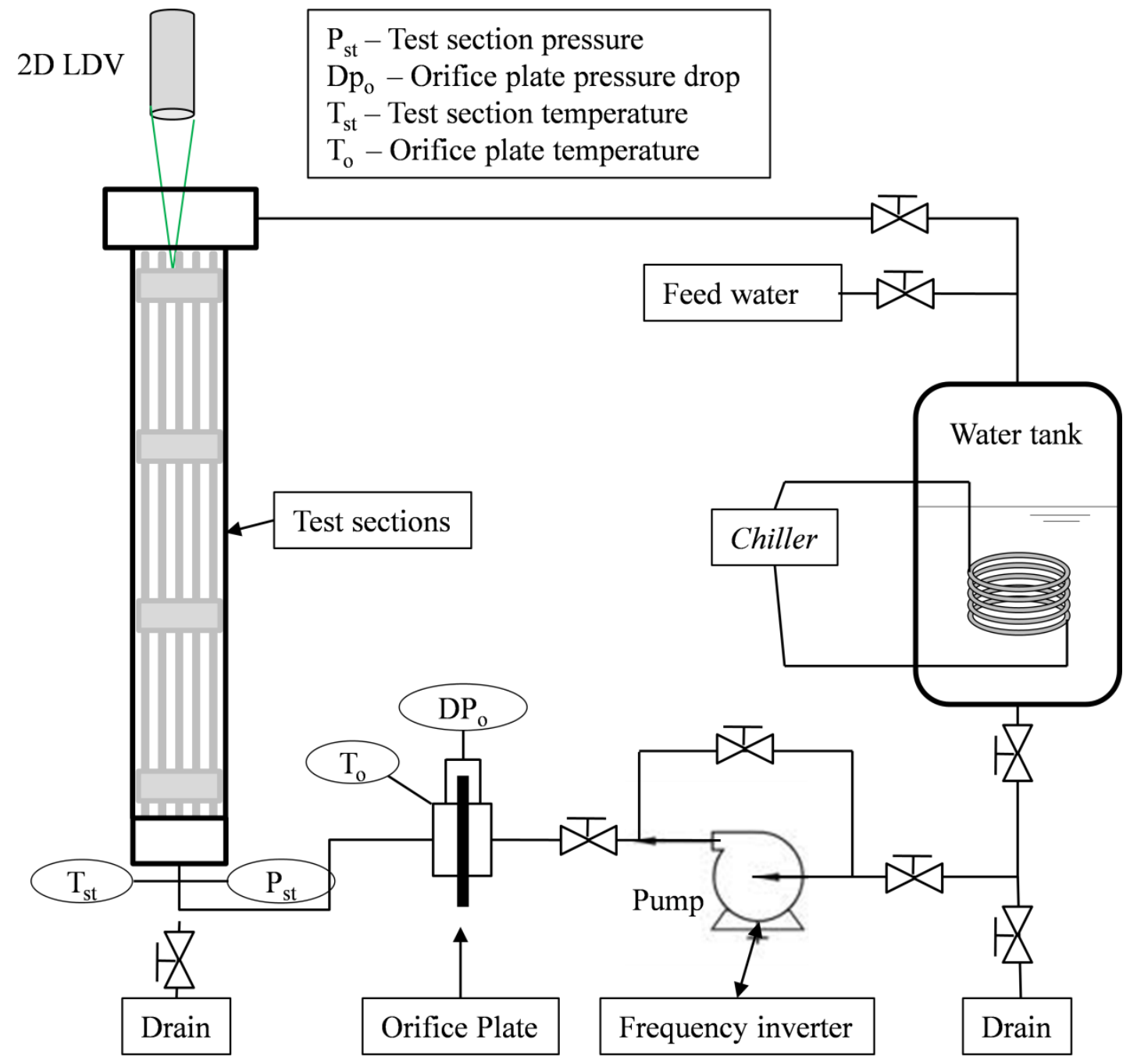

Figure 1: Hydraulic circuit.

Table 1: differential pressure transmitter

\begin{tabular}{c|c|c}
\hline Transmitter & Band [MPa] & Calibration Incertainty [kPa] \\
\hline 1 & 600.0 & 3.965 \\
\hline 2 & 100.0 & 579 \\
\hline
\end{tabular}


The environment temperature was monitored by a type $\mathrm{K}$ thermocouple. The temperature and pressure of water flow that were used in the experiment were kept at near-ambient conditions. When water flow temperature was elevated above $25{ }^{\circ} \mathrm{C}(298.15 \mathrm{~K})$ a chiller was used to remove this extra heat.

\subsection{The 2D LDV Measurement System}

The 2D-LDV (Laser Doppler Velocimetry) system has been used in velocities profile measurement. Two pair of beams from a 2D-LDV probe pass through the acrylic window of the tests section and converge in the water flow. Some particles with the similar density were dissolved in water to follow the flow. When these particles pass through the focal point of the beams they scatter the light back to the photo detector and this signal is acquired, processed and analyzed by Dantec software [11]. The main advantage of this technique is to measure velocities profiles without interfering in the flow, which makes it suitable for CFD comparisons. The 2D LDV probe was coupled to a XYZ automated positioning mechanism, as can be seen in the Figure 2, which is highly precise and warrants the high repeatability of the system. After this coupling an alignment process between 2DLDV probe, XYZ positioning mechanism, rod bundle and acrylic wall of test section was required to guarantee that the correct velocities profiles values were accounted in the measurement region. The measurement region can be seen in Figure 3 and this align process followed the pattern described in [12]. 

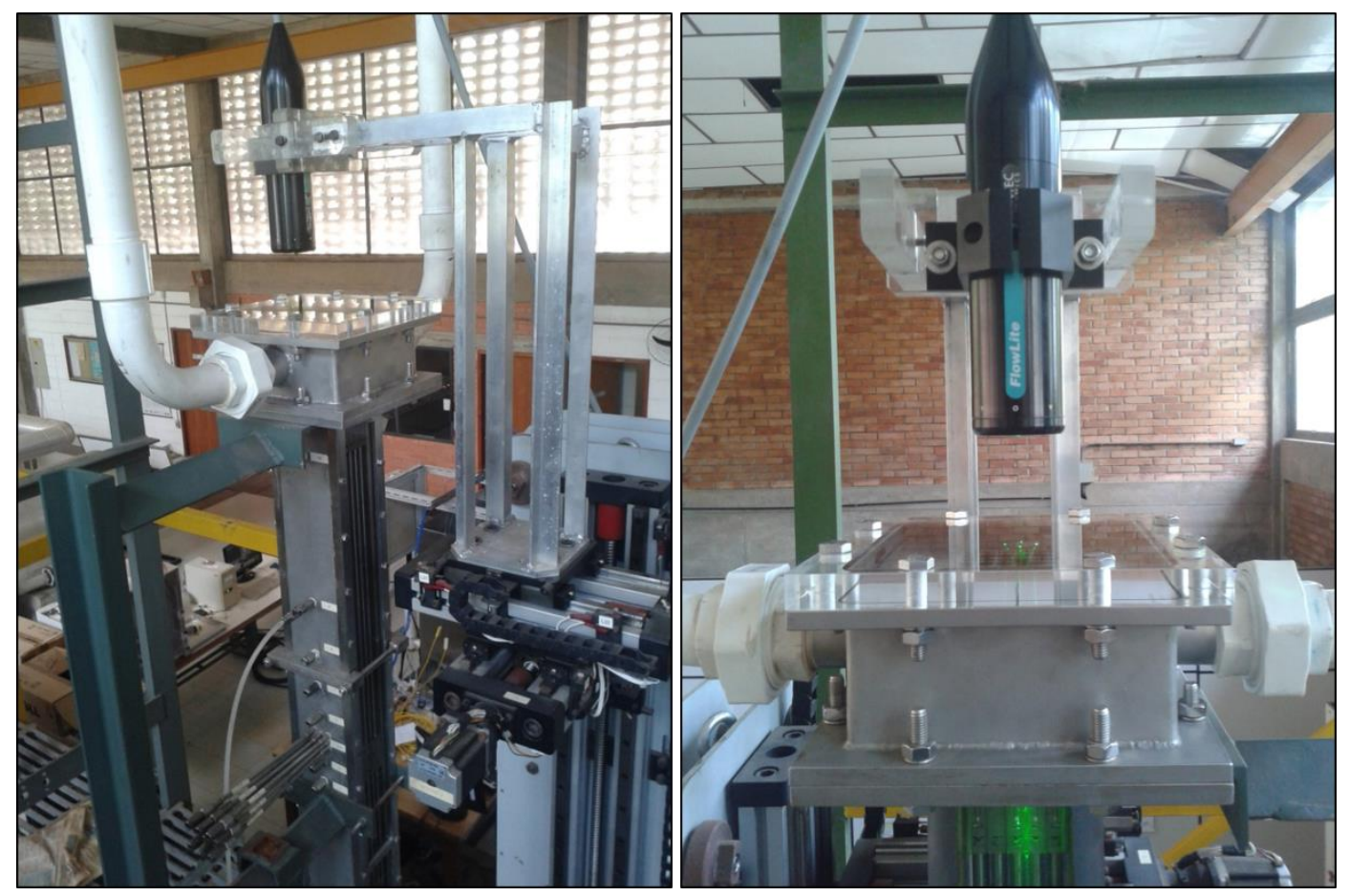

Figure 2: 2D-LDV system coupled in a XYZ positioning mechanism.

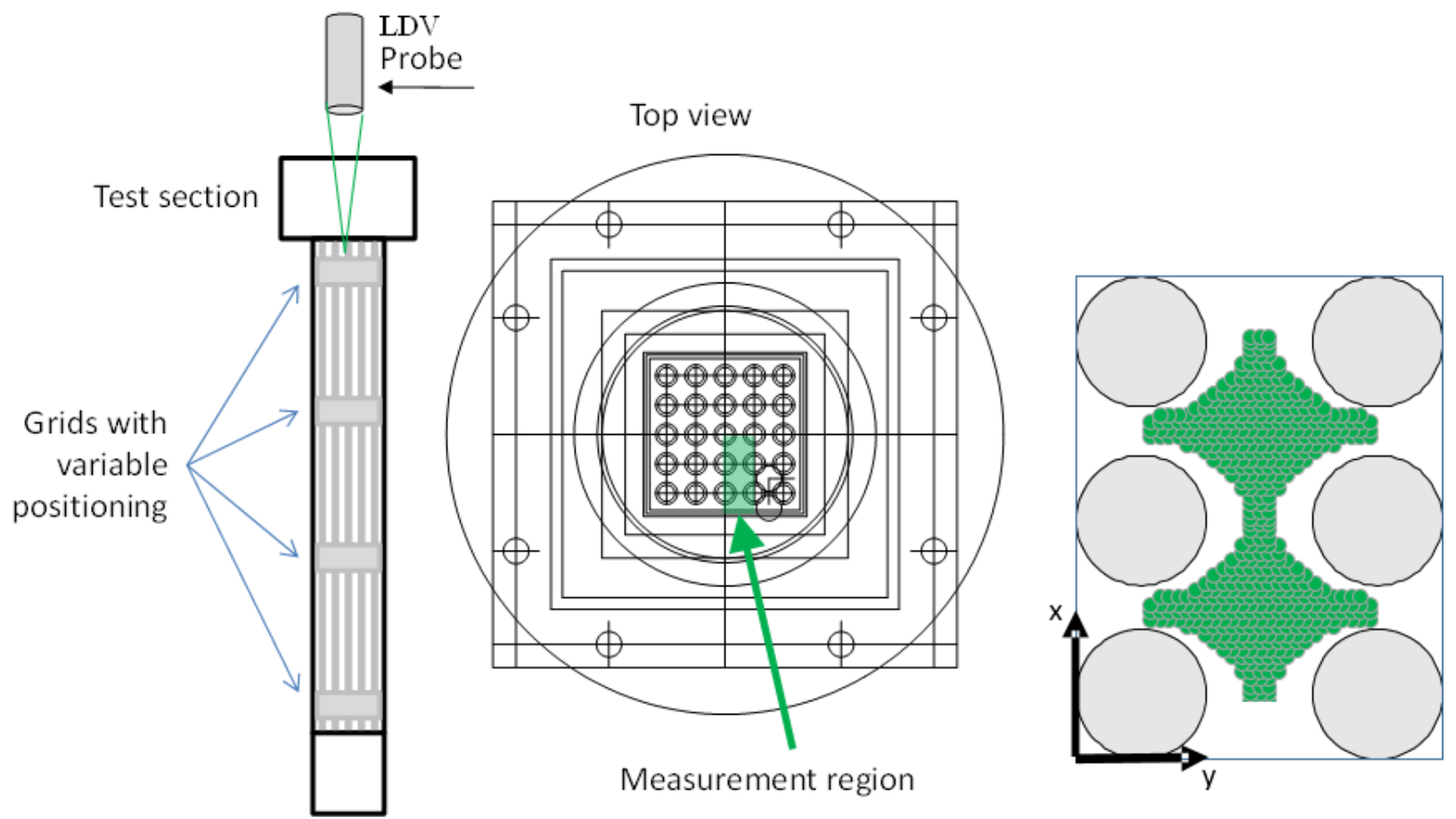

Figure 3: Measurement region. 
As shown in Figure 3, 505 measurement points were chosen between two subchannels at a plane $1.22 \mathrm{p}$ downstream the spacer grid in order to measure two velocities profiles components $\mathbf{u}$ and $\mathbf{v}$, in the $\mathrm{x}$ and $\mathrm{y}$ directions respectively. The experimental uncertainty was evaluated according to the Guide to the Expression of Uncertainty in Measurement - ISO GUM [13].

\section{NUMERICAL METHODOLOGY}

For the numerical simulation the commercial code ANSYS CFX 14.0 (2011) was choosen. The simulations were done in a cluster with 48 processing cores distributed in six computers (144 GB of RAM and 6 TB of storage capacity).

\subsection{The 2D LDV Measurement System}

A domain with the $5 \times 5$ fuel bundle and a spacer grid was simulated. With this domain, the same plane downstream the spacer grid was evaluated as the performed experiments. The complex geometry of the spacer grid, e.g. all details of springs, supports and welding spots were include in the geometry. The computational domain can be seen in the Figure 4. The red line represents the experimentally measured plane relative to the computational domain. 


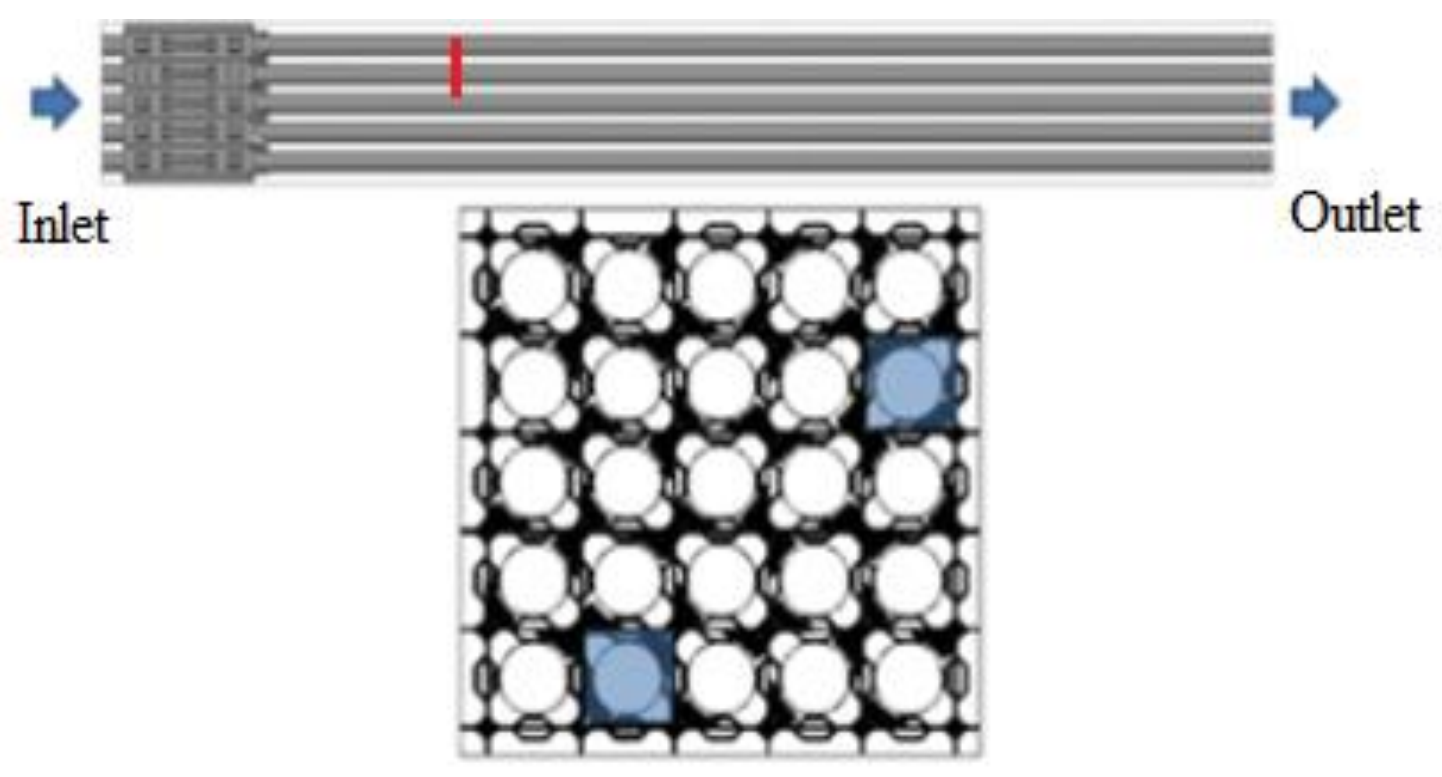

Figure 4: Computational domain.

Applied boundary conditions are presented Table 2. The physical properties of the water were considered constant and defined according to the table of IAPWS-IF97 [14], for the temperature and pressure of $26.32{ }^{\circ} \mathrm{C}(299.47 \mathrm{~K})$ and $0.37 \mathrm{MPa}$, respectively.

\subsection{Mesh and Numerical Parameters}

A non-structured mesh with hybrid elements was generated. The generated mesh has its core with tetrahedral elements and layers of prismatic elements (inflation) close to the walls of the rods and the spacer grid. A local refinement was applied to the spacer grid to capture the details of the flow in this region.

Mesh parameters where defined based on previous Verification and Validation study [15]. The mesh generated had 111,053,778 elements with 36,990,018 nodes. Near the walls, 7 layers of prismatic elements inflation was used. It is important to point out that the number of elements / nodes of the generated mesh demanded all the computational capacity available. An isometric view of the mesh next to the spacer grid is shown in Figure 5. 
Table 2: Boundary conditions for the spacer grid simulation

\begin{tabular}{c|c|c}
\hline Boundary & Condition & Values \\
\hline \multirow{2}{*}{ Inlet } & $\begin{array}{c}\text { Uniform dimensionless axial velocity } \\
\text { Turbulence intensity }\end{array}$ & $1[-]$ \\
& Average relative static pressure \\
\hline Outlet & No-slip walls & $0[\mathrm{~Pa}]$ \\
\hline Rod, walls and grid surfaces & & Smooth wall \\
\hline
\end{tabular}

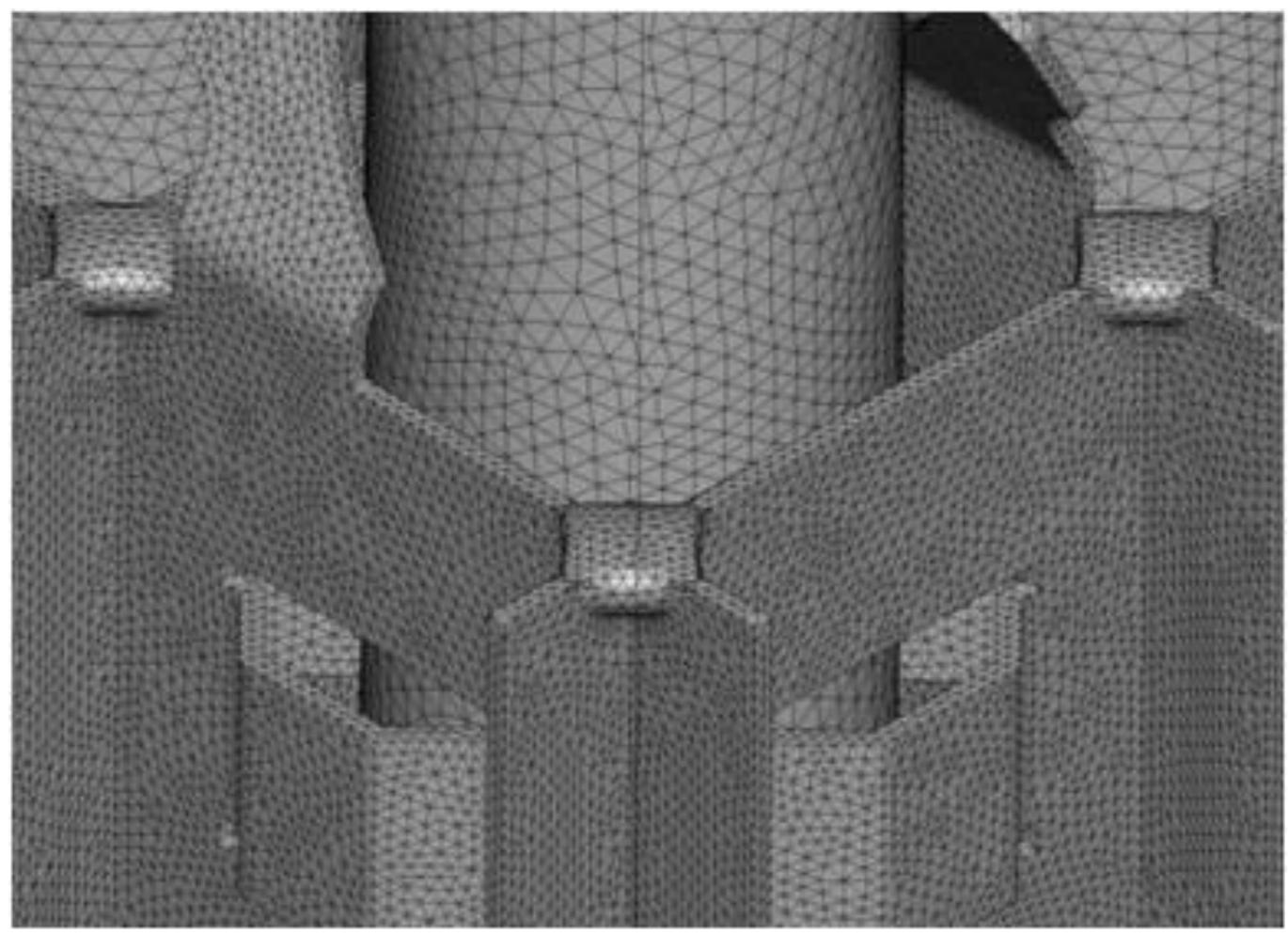

Figure 5: Isometric view of the mesh. 
The simulations were performed using second order discretization schemes for the steady state RANS equations. The turbulence model RNG $\mathrm{k}-\varepsilon$ was used based on previous numerical study (Santos et al., 2013).

The simulations were performed in double precision with a residual target of $10^{-7}$ of the averaged square root (RMS). This convergence residual was set to minimize the uncertainty due to the iterative solution of the equations accordingly to [6] and [17].

\section{RESULTS AND ANALYSIS}

In Table 3 it can be seen the uncertainty evaluated for Re, pressure $[\mathrm{Pa}]$ and temperature $[\mathrm{K}]$ in the experiments performed. A total of six tests were done.

Table 3: Experimental conditions of the water flow.

\begin{tabular}{cccccc}
\hline $\operatorname{Re}\left[10^{3}\right]$ & $\mathrm{U}\left[10^{3}\right]$ & $\mathrm{T}[\mathrm{K}]$ & $\mathrm{U}[\mathrm{K}]$ & $\mathrm{P}[\mathrm{kPa}]$ & $\mathrm{U}[\mathrm{kPa}]$ \\
\hline 53.67 & 0.54 & 298.15 & 274.14 & 277 & 1 \\
\hline
\end{tabular}

Figure 6 shows the experimental result for the velocities vector field at the plane located at the height equal to $1.22 \mathrm{p}$ downstream of the spacer grid. Velocity magnitude is presented normalized by the average bulk velocity $(<\mathrm{w}>)$ and position is normalized by the pitch $(\mathrm{p})$. The mean normalized expanded uncertainty of velocity was $1.24 \%$ for $95 \%$ confidence interval. Figure 7 shows the numerical result that were simulated for the same conditions obtained experimentally. 


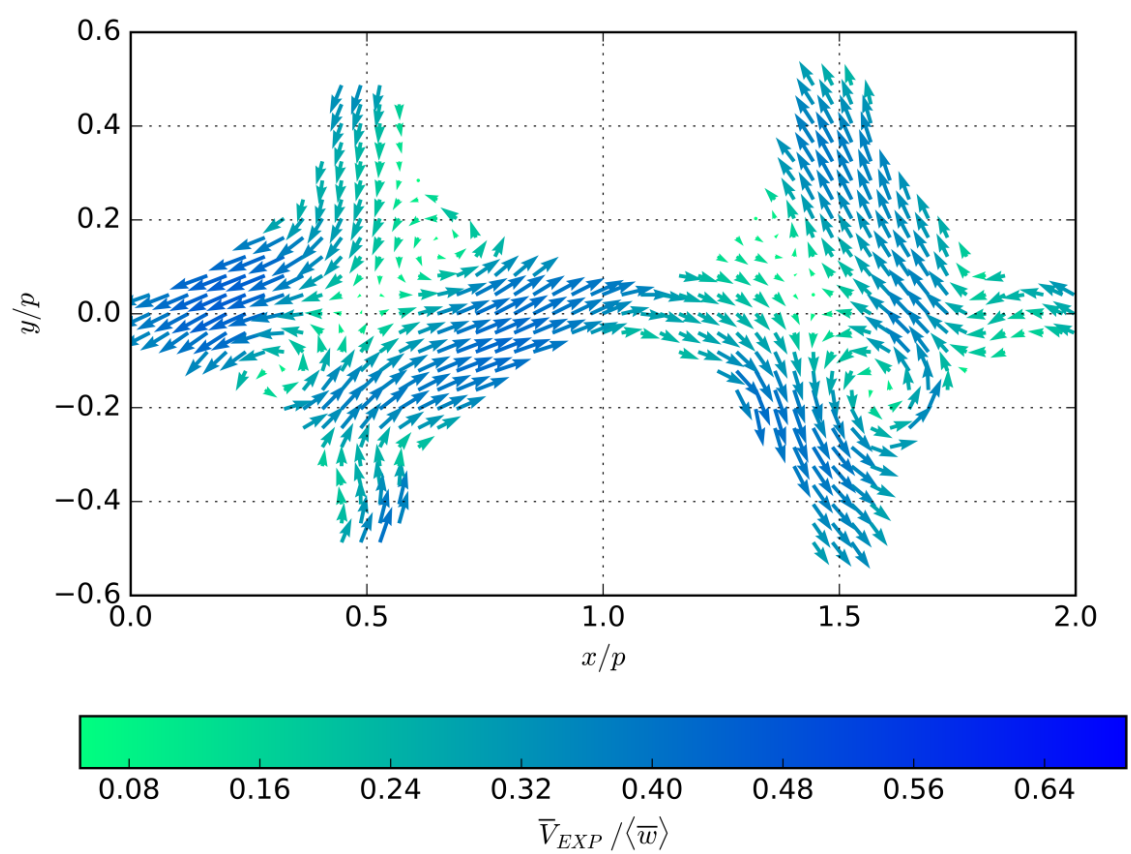

Figure 6: Velocity profile field for $1.22 p$ height at downstream spacer grid for $\operatorname{Re}=5.4 \times 10^{4}$ obtained by Experiments.

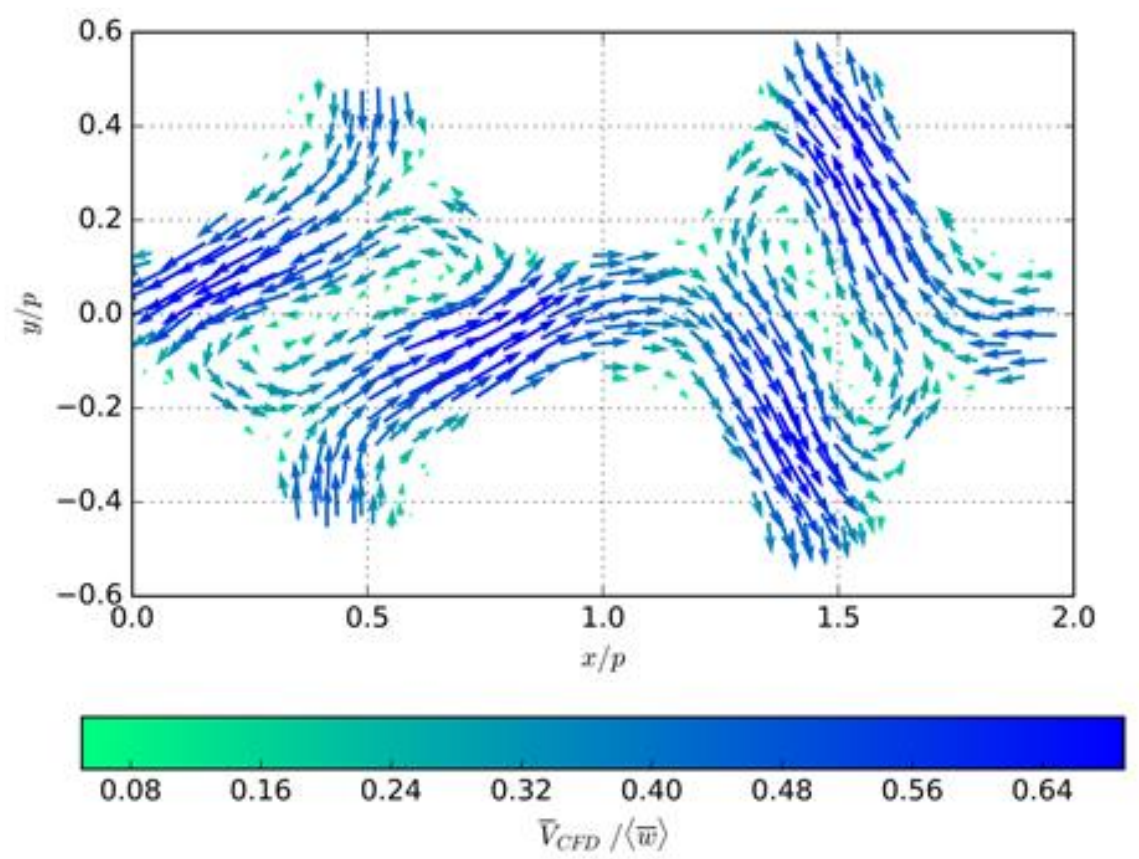

Figure 7: Velocity profile field for $1.22 p$ height at downstream spacer grid for $\mathrm{Re}=5.4 \times 10^{4} \mathrm{ob}-$ tained by CFD simulations. 
As can be seen in both Figures 6 and 7 the velocity vector field show good qualitative agreement between the CFD model and the experiments. The same behavior of the flow mixing and vortex structures can be seen. Both results show the cross-flow and the swirl-flow in the same direction, similar intensity and can be pointed out that the cross-flow stood out more than the swirl-flow. The swirl-flow was observed in center of both sub channels and secondary vortices were found nearby rods. On the other hand, the numerical velocity vector field obtained was $8 \%$ higher than experimental in terms of overall magnitude.

\section{CONCLUSIONS}

In this study, methodologies used to evaluate flow field characteristics downstream spacer grids numerically and experimentally were presented. A 2D-LDV system was used to obtained a velocity vector field at two subchanels $1.22 \mathrm{p}$ downstream a vaned spacer grid. The same experimental conditions were simulated by a commercial CFD code and the results were qualitatively compared.

Results showed good qualitative agreement between CFD and experimental for the velocity field evaluated which indicate that the pursued methodologies are consistent and will be able to produce meaningful results in future explorations.

This study is part of an ongoing study, and further results and analysis will be performed and presented in future publications. The presented methods will be applied to the study of different types of spacer grids and flow conditions in rod bundles, such as in accident and blockage scenarios.

\section{ACKNOWLEDGMENTS}

This research project is supported by the following Brazilian institutions: Universidade Federal de Minas Gerais (UFMG), Nuclear Technology Development Center (CDTN), Brazilian Nuclear 
Energy Commission (CNEN), Research Support Foundation of the State of Minas Gerais (FAPEMIG) project PPP APQ-01242-14 and Brazilian Council for Scientific and Technological Development (CNPq) project Universal 427868/2016-5 and Coordenação de Aperfeiçoamento de Pessoal de Nível Superior (CAPES).

\section{REFERENCES}

1. TODREAS, N. E., and KAZIMI, M.S. Nuclear Systems Vol 1: Thermal Hydraulic. Fundamentals, Ed.CRC Press, New York \& United States of America, 2012.

2. CONNER, M. E., HASSAN, Y. A., and DOMINGUES-ONTIVEROS, E.E., Hydraulic Benchmark Data for PWR Mixing Vane Grid, Nuclear Engineering and Design, v. 264, p. 97-102, 2013.

3. IN, W. K., SHIN, C. H., OH, D.S., and CHUN, T. H., Experimental Observation and CFD Prediction of Flow Mixing in a Rod Bundle with Mixing-vane Spacer Grid, In: 10TH PACIFIC SYMPOSIUM ON FLOW VISUALIZATION AND IMAGE PROCESSING, 2015, Naples. E-Book Proceedings... pp. 247.

4. KANG, S. K., and HASSAN, Y. A., Computational fluid dynamics (CFD) round robin benchmark for a pressurized water reactor (PWR) rod bundle, Nuclear Engineering and Design, v. 301, p. 204-231, 2016.

5. CHANG, S. K., KIM, S., and SONG, C.H., Turbulent mixing in a rod bundle with vaned spacer grids, Nuclear Engineering and Design, v. 279, p. 19-36, 2014.

6. SANTOS, A. A. C., CHILDS, M., NGUYEN, T. D., and HASSAN, Y., Convergence study and uncertainty quantification of average and statistical PIV measurements in a matched re- 
fractive index 5x5 rod bundle with mixing vane spacer grid, Experimental Thermal and Fluid Science, v. 102, p. 215-231, 2019.

7. ANSYS, IC, CFX-13 Pre Users Guide, Release 13.0, Canonsburg: ANSYS, 2012. 344p.

8. ISO 5167-1, Measurement of fluid flow by means of pressure differential devices, ISO, Geneva, Switzerland, 1991.

9. NAVARRO, M.A., Procedimento para calibração dos transmissores de pressão do circuito água-ar (CAA), Nota interna CNEN/CDTN, 2011.

10. NAVARRO, M.A., Procedimento para calibração das linhas de medição de temperatura do circuito água-ar (CAA), Nota interna CNEN/CDTN, 2012.

11. BSA Flow Software, BSA Flow Software Version 4.10 Instalation \& Users Guide, Dantec Dynamics A/S, Denmark, 2006.

12. CASTRO, H. F. P., Investigação Experimental do Escoamento de Água Após Grade Espaçadora de Elemento Combustível Para Reatores Nucleares do Tipo PWR, Dissertação, Programa de Pós Graduação do Centro de Desenvolvimento da Tecnologia Nuclear, Belo Horizonte, Brazil, 2016.

13. ISO GUM, JCGM, Evaluation of measurement data Guide to the expression of uncertainty in measurement, 2008.

14. KRETZSCHMAR, H., COOPER, J. R., GALLAGHER, J. S., HARVEY, A. H., KNOBLOCH, K., MARES, R., MIVAGAWA, K., OKITA, N., SPAN, R., STÖCKER, I., WAGNER, W., and WBER, I., IAPWS Industrial Formulation 1997 for the Thermodynamic Properties of Water and Steam, Journal of Engineering for Gas Turbines and Power ASME, v. 122, p. 150-182, 2000. 
15. SANTOS, A. A. C., FILHO, J. A. B., and NAVARRO, M., A. Verification and validation of a PWR rod bundle segment CFD simulation, In: 15th International Topical Meeting on Nuclear Reactor Thermal-hydraulics - NURETH-15, Pisa, 2013.

16. IN W. K., LEE, K., and SHIN, C.H. Application of Computational Fluid Dynamics to the Flow Mixing and Heat Transfer in Rod Bundle., In: Tenth International Conference on Computational Fluid Dynamics - ICCFD10-045, 2018, Barcelona, Proceedings... p. 0115 .

17. VIDAL, G. A. M.; Investigação Numérica do Escoamento de água Através de Grades Espaçadoras de Elementos Combustíveis Nucleares, Trabalho de Conclusão de Curso, Universidade Federal de Minas Gerais, Belo Horizonte, Brazil, 2018. 